\title{
Transcriptome analysis reveals key roles of AtLBR-2 in LPS-induced defense responses in plants
}

\author{
Sayaka lizasa ${ }^{1,2,3}$, Ei'ichi lizasa ${ }^{4}$, Keiichi Watanabe ${ }^{2,3}$ and Yukio Nagano ${ }^{1,3^{*}}$
}

\begin{abstract}
Background: Lipopolysaccharide (LPS) from Gram-negative bacteria cause innate immune responses in animals and plants. The molecules involved in LPS signaling in animals are well studied, whereas those in plants are not yet as well documented. Recently, we identified Arabidopsis AtLBR-2, which binds to LPS from Pseudomonas aeruginosa (pLPS) directly and regulates pLPS-induced defense responses, such as pathogenesis-related 1 (PR1) expression and reactive oxygen species (ROS) production. In this study, we investigated the PLPS-induced transcriptomic changes in wild-type (WT) and the at/br-2 mutant Arabidopsis plants using RNA-Seq technology.

Results: RNA-Seq data analysis revealed that pLPS treatment significantly altered the expression of 2139 genes, with 605 up-regulated and 1534 down-regulated genes in WT. Gene ontology (GO) analysis on these genes showed that GO terms, "response to bacterium", "response to salicylic acid (SA) stimulus", and "response to abscisic acid (ABA) stimulus" were enriched amongst only in up-regulated genes, as compared to the genes that were down-regulated. Comparative analysis of differentially expressed genes between WT and the at/br-2 mutant revealed that 65 genes were up-regulated in WT but not in the atlbr-2 after pLPS treatment. Furthermore, GO analysis on these 65 genes demonstrated their importance for the enrichment of several defense-related GO terms, including "response to bacterium", "response to SA stimulus", and "response to ABA stimulus". We also found reduced levels of pLPS-induced conjugated SA glucoside (SAG) accumulation in atlbr-2 mutants, and no differences were observed in the gene expression levels in SA-treated WT and the atlbr-2 mutants.
\end{abstract}

Conclusion: These 65 AtLBR-2-dependent up-regulated genes appear to be important for the enrichment of some defense-related GO terms. Moreover, AtLBR-2 might be a key molecule that is indispensable for the up-regulation of defense-related genes and for SA signaling pathway, which is involved in defense against pathogens containing LPS.

Keywords: Plant immunity, Defense response, Lipopolysaccharide, RNA-Seq, Arabidopsis, Salicylic acid

\section{Background}

The endotoxin lipopolysaccharide (LPS), a major component of the outer membranes of Gram-negative bacteria, is one of the most studied pathogen-associated molecular patterns (PAMPs). The perception of LPS triggers various defense responses in plants and animals [1]. In plants, LPS-induced defense responses have been well studied; these include LPS-induced generation of reactive oxygen

\footnotetext{
* Correspondence: nagano@cc.saga-u.ac.jp

${ }^{1}$ Analytical Research Center for Experimental Sciences, Saga University, Saga, Japan

${ }^{3}$ Department of Biological Science and Technology, The United Graduate School of Agricultural Sciences, Kagoshima University, Kagoshima, Japan Full list of author information is available at the end of the article
}

species (ROS) and nitrogen oxide (NO), salicylic acid (SA) accumulation, expression of pathogenesis-related (PR) genes, and stomatal closure [2-5]. SA, in particular, is an important signal molecule in plant defense. The accumulation of SA is involved in local defenses as well as in systemic acquired resistance (SAR) [6].

The LPS recognition mechanism has been well studied in animals. In mammals, LPS-binding protein (LBP) and bactericidal/permeability-increasing protein (BPI) play important roles in the regulation of immune responses against LPS [7]. Although both the proteins directly bind to LPS, BPI inhibits whereas LBP enhances the binding of LPS to Toll-like receptor 4, a mammalian LPS receptor. Recently, we identified two Arabidopsis LBP/BPI- 
related proteins, AtLBR-1 and AtLBR-2 [8]. When we incubated recombinant forms of both AtLBR-1 and AtLBR-2 with Pseudomonas aeruginosa LPS (pLPS) separately, they exhibited the capability to bind to it directly; atlbr mutants showed deficiencies in pLPSinduced PR1 gene expression and ROS generation. We predicted that AtLBR-2 would be more important than AtLBR-1 in the induction of defense responses to LPS because the binding affinity of AtLBR-2 for LPS appeared higher than that of AtLBR-1, and AtLBR-2 is located in the apoplastic region.

In the present study, we investigated the importance of AtLBR-2 in the dynamic changes in Arabidopsis transcriptome in response to LPS treatment. To achieve this goal, we performed a transcriptome analysis using highthroughput mRNA sequencing (RNA-Seq). RNA-Seq analysis using WT and the atlbr-2-1 identified 65 AtLBR-2dependent genes that were up-regulated after LPS treatment. These 65 genes appear to be important for the enrichment of some defense-related gene ontology (GO) terms. Our findings highlight the indispensable role of AtLBR-2 in defense signaling mechanism against LPS.

\section{Results}

Transcriptomic analysis of $P$. aeruginosa LPS-responsive genes in WT Arabidopsis

To examine and compare the LPS-induced transcriptional changes between wild-type (WT) and the atlbr-21 , we treated them with LPS from $P$. aeruginosa (pLPS); total RNA was extracted and RNA-Seq analysis was performed.

Firstly, we analyzed the pLPS-responsive genes in the WT. The RNA-Seq data obtained from untreated WT were compared with that of pLPS-treated WT. We observed that the transcript levels of 2139 genes changed significantly in pLPS-treated WT. Of these, 605 genes were identified as upregulated genes in pLPS-treated WT (Fig. 1a). Moreover, 1534 genes were identified as down-regulated genes in pLPStreated WT (Fig. 1b). We performed gene ontology (GO) analysis of these genes using the functional annotation chart of DAVID. The biological process (BP) GO classification of the 605 up-regulated genes identified $33 \mathrm{GO}$ terms $(P<0.01$, Fig. 2, blue line) (Additional file 1: Table S1), including not only defense-related GO terms, but also several metabolic processes-related terms. This finding corresponded with the results reported from transcriptional analysis on Arabidopsis seedlings treated with LPS from Burkholderia cepacia [9]. Defense-related GO terms included, "response to bacterium", "response to SA stimulus", "response to abscisic acid (ABA) stimulus", "response to jasmonic acid stimulus", "response to ROS", and "response to wounding". In contrast, 1534 downregulated genes were classified via 43 GO terms $(P<0.01)$ (Additional file 1: Table S2). Interestingly, defense-related GO terms, other than "response to bacterium", "response to SA

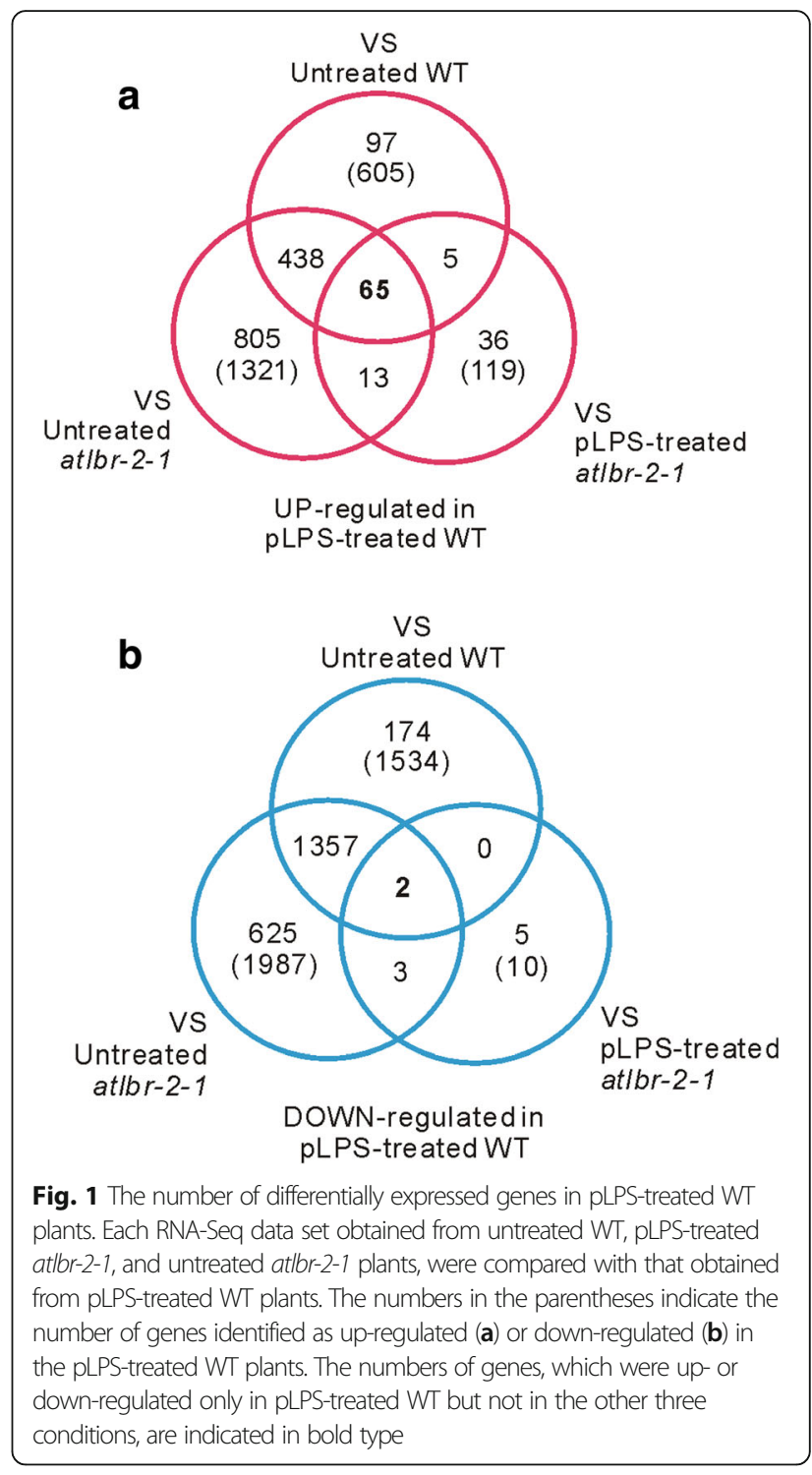

stimulus", "response to ABA stimulus", were also common in these 43 GO terms. These findings suggested that upregulation, but not down-regulation, of genes related to bacterial responses may be a characteristic of normal pLPSinduced gene expression. It can also be inferred that SA- and ABA-related pathways may be important for the upregulation, but not down-regulation, of genes after pLPS treatment.

Furthermore, cellular component (CC) GO analysis showed that $23.0 \%$ of the 605 up-regulated genes were categorized as "endomembrane system"; also, $22.9 \%$ and $11.9 \%$ of the 1534 down-regulated genes were categorized as "endomembrane system" and "intrinsic to membrane", respectively (Additional file 1: Table S3). These results indicated that genes activated in the membrane-related region were most affected by the pLPS treatment. 


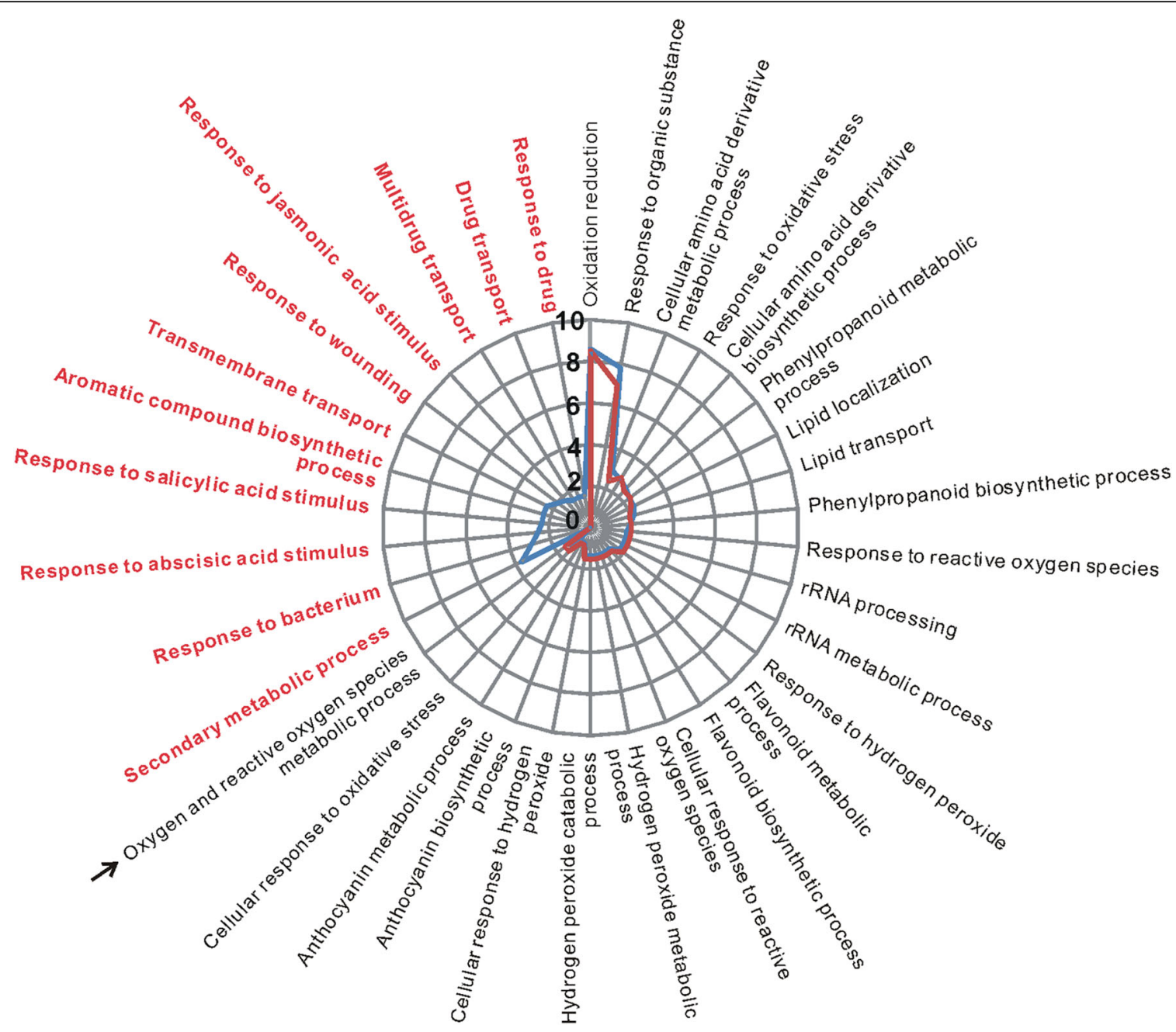

Fig. 2 GO classification of pLPS-responsive up-regulated genes. BP GO terms obtained from the GO analysis of 605 pLPS-induced up-regulated genes in WT are shown with the blue line. The same analysis conducted with 540 genes, which excluded 65 AtLBR-2-dependent up-regulated genes from the 605 genes, are shown with the red line. The red font highlights no enriched GO terms in the 540 genes. An arrow indicates the $\mathrm{GO}$ term identified only in 540 genes. Scale of $y$ axis shows the percentage of genes that are annotated for each biological process. $P<0.01$

\section{Identification of AtLBR-2-dependent up- or down- regulated genes}

To elucidate the importance of AtLBR-2 in pLPSinduced transcriptional responses, we identified the genes that were up-regulated in an AtLBR-2-dependent manner after $24 \mathrm{~h}$ of pLPS treatment. We compared each of the three RNA-Seq data with that of pLPS-treated WT (Fig. 1). Furthermore, we studied the genes that were up- or down-regulated only in the pLPS-treated WT plants and not in the other 3 data sets; these were then identified as AtLBR-2-dependent up- or down-regulated genes. A total of 65 candidate genes were identified to be AtLBR-2-dependent upregulated genes (Fig. 1a, Table 1). We focused on these 65 genes and analyzed them further; only two genes, "unfertilized embryo sac 11 (UNE11: AT4G00080)" and the gene for an "uncharacterized protein (AT3G20340)", were identified to be AtLBR-2-dependent downregulated genes (Fig. 1b).

\section{AtLBR-2 is indispensable for pLPS-induced defense- related GO terms}

To determine the importance of the 65 AtLBR-2dependent up-regulated genes in the GO classification of 605 up-regulated genes, we performed GO analysis for 540 genes, excluding the above-mentioned 65 genes from the 605 up-regulated genes $(P<0.01$, Fig. 2 , red line) (Additional file 1: Table S1). Comparing the results of the GO analysis revealed that 540 genes showed no enrichment for defense-related GO terms, including responses to bacterium, SA stimulus, ABA stimulus, wounding, and drug. These results highlight the importance of 65 genes in defense-related GO terms, and 
Table 1 AtLBR-2-dependent up-regulated 65 genes after pLPS treatment

\begin{tabular}{|c|c|c|c|}
\hline Accession & Description & $\log _{2} \mathrm{FC}$ & Ref. \\
\hline AT2G14610 & Pathogenesis-related protein 1 (PR1)* & -5.493297 & [43] \\
\hline AT3G23120 & Receptor like protein 38 (RLP38)* & -4.553003 & [44] \\
\hline AT3G21500 & 1-deoxy-D-xylulose 5-phosphate synthase 1 (DXPS1) & -4.454822 & - \\
\hline AT2G30770 & Putative cytochrome P450 (CYP71A13)* & -3.876201 & [17] \\
\hline AT1G61800 & Glucose-6-phosphate/phosphate transporter 2 (GPT2)* & -3.440655 & {$[45,46]$} \\
\hline AT1G21320 & Nucleotide binding protein & -3.423526 & - \\
\hline AT2G14560 & Late upregulated in response to Hyaloperonospora parasitica 1 (LURP1)* & -3.420434 & [47] \\
\hline AT4G35180 & LYS/HIS transporter 7 (LHT7)* & -3.326263 & {$[44,46]$} \\
\hline AT2G29350 & Senescence-associated gene 13 (SAG13)* & -3.152003 & [48] \\
\hline AT4G04510 & Cysteine-rich receptor-like kinase (RLK) 38 (CRK38)* & -3.124063 & [49] \\
\hline AT2G24850 & Tyrosine aminotransferase 3 (TAT3)* & -2.935669 & [10] \\
\hline AT2G18660 & Plant natriuretic peptide A (PNP-A)* & -2.824188 & [50] \\
\hline AT5G24200 & Alpha/beta-Hydrolases superfamily protein* & -2.675765 & [51] \\
\hline AT2G04070 & Multidrug and Toxin Extrusion (MATE) efflux family protein & -2.651088 & - \\
\hline AT3G22235 & Pathogen and circadian controlled 1 (PCC1) & -2.612637 & - \\
\hline AT4G12470 & Azelaic acid induced 1 (AZI1)* & -2.593354 & [52] \\
\hline AT1G33960 & avrRpt2-induced gene 1 (AIG1)* & -2.454032 & [53] \\
\hline AT1G65500 & Uncharacterized protein & -2.423526 & [45] \\
\hline AT4G22470 & Lipid transfer protein (LTP) family protein* & -2.414268 & [54] \\
\hline AT4G12490 & Lipid transfer protein* & -2.37707 & [55] \\
\hline AT4G12480 & Early Arabidopsis aluminum induced 1 (pEARLI 1$)^{*}$ & -2.334243 & [56] \\
\hline AT5G46050 & Peptide transporter 3 (PTR3)* & -2.322650 & [57] \\
\hline AT3G28580 & P-loop containing nucleoside triphosphate hydrolases superfamily protein & -2.314015 & - \\
\hline AT3G50480 & Homolog of RPW8 4 (HR4)* & -2.311148 & [10] \\
\hline AT2G26400 & Acireductone dioxygenase 3 (ARD3) & -2.302582 & - \\
\hline AT1G51820 & Leucine-rich repeat protein kinase family protein* & -2.288417 & [32] \\
\hline AT1G02920 & Glutathione S-transferase 7 (GSTF7)* & -2.267427 & [58] \\
\hline AT1G65481 & Uncharacterized protein & -2.255667 & - \\
\hline AT1G43910 & P-loop containing nucleoside triphosphate hydrolases superfamily protein* & -2.252226 & [44] \\
\hline AT4G17660 & Protein kinase superfamily protein & -2.126580 & - \\
\hline AT4G26200 & 1-Amino-cyclopropane-1-carboxylate synthase (ACS7) & -2.091110 & - \\
\hline AT3G63380 & Auto-inhibited $\mathrm{Ca}^{2+}$-ATPase $12(\mathrm{ACA} 12)^{*}$ & -2.063108 & {$[24,44]$} \\
\hline AT5G09470 & Dicarboxylate carriers 3 (DIC3) & -2.058293 & - \\
\hline AT4G12735 & Uncharacterized protein & -2.022097 & - \\
\hline AT2G25470 & Receptor like protein 21 (RLP21) & -2.002310 & - \\
\hline AT3G26210 & Putative cytochrome P450 (CYP71B23) & -1.987360 & - \\
\hline AT4G23130 & Cysteine-rich RLK 5 (CRK5)* & -1.985073 & [59] \\
\hline AT2G25510 & Uncharacterized protein* & -1.984502 & [10] \\
\hline AT5G03350 & Legume lectin family protein* & -1.980512 & [10] \\
\hline AT3G50770 & Calmodulin-like $41($ CLM41)* & -1.936221 & [55] \\
\hline AT4G37990 & Elicitor-activated gene 3-2 (ELI3-2)* & -1.895395 & [60] \\
\hline AT4G00170 & Plant vesicle-associated membrane protein (VAMP) family protein & -1.809448 & - \\
\hline AT2G19190 & Flg22-induced RLK 1 (FRK1)* & -1.804904 & [61] \\
\hline AT2G20720 & Pentatricopeptide repeat (PPR) superfamily protein & -1.790359 & - \\
\hline
\end{tabular}


Table 1 AtLBR-2-dependent up-regulated 65 genes after pLPS treatment (Continued)

\begin{tabular}{|c|c|c|c|}
\hline Accession & Description & $\log _{2} \mathrm{FC}$ & Ref. \\
\hline AT5G44390 & FAD-binding Berberine family protein & -1.785875 & - \\
\hline AT1G35230 & Arabinogalactan-protein 5 (AGP5)* & -1.779422 & [62] \\
\hline AT5G53870 & Early nodulin-like protein 1 (ENODL1) & -1.774478 & - \\
\hline AT2G04050 & Multidrug and Toxin Extrusion (MATE) efflux family protein & -1.766112 & - \\
\hline AT1G02930 & Glutathione S-transferase 6 (GSTF6)* & -1.750494 & [63] \\
\hline AT2G43620 & Chitinase family protein* & -1.717382 & [64] \\
\hline AT1G21250 & Cell wall-associated kinase 1 (WAK1)* & -1.706512 & {$[10,65]$} \\
\hline AT1G80130 & Tetratricopeptide repeat (TPR)-like superfamily protein* & -1.679920 & [66] \\
\hline AT5G44575 & Uncharacterized protein & -1.671623 & - \\
\hline AT5G62480 & Glutathione S-transferase TAU 9 (GSTU9) & -1.630394 & - \\
\hline AT5G10760 & Apoplastic, EDS1-dependent 1 (AED1)* & -1.621488 & [50] \\
\hline AT5G24640 & Uncharacterized protein & -1.616614 & - \\
\hline AT5G64000 & $3^{\prime}\left(2^{\prime}\right), 5^{\prime}$-bisphosphate nucleotidase (SAL2) & -1.600337 & - \\
\hline AT3G28540 & P-loop containing nucleoside triphosphate hydrolases superfamily protein & -1.584674 & - \\
\hline AT1G05730 & Uncharacterized protein (DUF842) & -1.542038 & - \\
\hline AT1G26420 & FAD-binding Berberine family protein & -1.526992 & [67] \\
\hline AT1G67520 & Lectin protein kinase family protein & -1.478748 & - \\
\hline AT2G26440 & Pectin methylesterase 12 (PME12)* & -1.460767 & [68] \\
\hline AT3G26830 & Phytoalexin deficient 3 (PAD3)* & -1.409278 & {$[16,69]$} \\
\hline AT2G41730 & Uncharacterized protein & -1.405069 & - \\
\hline AT1G15520 & Pleiotropic drug resistance 12 (PDR12)* & -1.361787 & [70] \\
\hline
\end{tabular}

Genes up-regulated in an AtLBR-2-dependent manner after $24 \mathrm{~h}$ pLPS treatment were identified (FDR $<0.01$, Log 2 FC $<-1.35)$. Genes, which were related to plant-pathogen interaction or to SA, are indicated by asterisks or in bold type, respectively, with references

demonstrate that AtLBR-2 might be indispensable for the expression of pLPS-induced defense-related genes.

\section{Characterization of 65 AtLBR-2-dependent up-regulated genes}

The details of the 65 pLPS-induced AtLBR-2-dependent up-regulated genes are shown in Table 1 . We expected that PR1 would be one of the 65 AtLBR-2-dependent upregulated genes, because we previously reported that atlbr mutants showed deficiencies in the expression of pLPSinduced PR1 (AT2G14610) [8]. Consistent with our prediction, as shown in Table 1, PR1 was the most differentially-expressed gene among the AtLBR-2dependent up-regulated genes. Furthermore, most of the 65 genes have been reported to be associated with plantpathogen interaction and with SA-regulated responses.

These 65 genes were also annotated to each of the three GO categories; CC, molecular function (MF), and BP. These genes were assigned the CC GO terms, "endomembrane system" (27.1\%), "membrane" (17.1\%), and "membrane-bound organelle" (11.4\%, Table 2$)$. Thus, approximately $50 \%$ of these genes were categorized as membrane-related CC GO terms, highlighting the interrelationship between the proteins encoded by these genes and AtLBR-2 [8]. Furthermore, the MF GO terms related to catalytic (44.1\%), binding (35.3\%), and transporter (11.8\%) activities were mostly enriched. They were also predicted to participate in $25 \mathrm{BP}$ GO terms, mainly in the "response to stress" (12.0\%), "cellular metabolic process" (10.6\%), "response to biotic stimulus" (9.2\%), and in "response to other organisms" (9.1\%). Thus, interestingly, approximately $50 \%$ of these genes were involved in response to stress and stimuli. To further define the functions of these 65 genes, the enriched pathways were identified by KOBAS (Table 3 ). The pathway analysis also revealed that the 65 genes were involved in defense-related pathways, including "camalexin biosynthesis", "glutathione-mediated detoxification II", and "plant-pathogen interaction".

\section{atlbr-2-1 mutants showed defect in up-regulation of six} pLPS-induced genes

To confirm the RNA-Seq results of AtLBR-2-dependent up-regulated genes, we assigned and tested several genes involved in plant-pathogen interaction by conducting quantitative RT-PCR (qRT-PCR) using appropriate primers (Additional file 1: Table S4; Fig. 3). In all of the tested 6 genes, putative cytochrome P450 (CYP71A13), late upregulated in response to Hyaloperonospora parasitica (LURP1), plant natriuretic peptide A (PNP-A), 
Table 2 GO-term-enriched tables of AtLBR-2-dependent up-regulated 65 genes

\begin{tabular}{|c|c|}
\hline CC GO term & $\%$ \\
\hline Endomembrane system & 27.1 \\
\hline Membrane & 17.1 \\
\hline Intercellular part & 14.3 \\
\hline Membrane-bound organelle & 11.4 \\
\hline Intercellular organelle & 11.4 \\
\hline External encapsulation structure & 8.6 \\
\hline Apoplast & 4.3 \\
\hline Membrane part & 1.4 \\
\hline Intercellular organelle part & 1.4 \\
\hline Organelle membrane & 1.4 \\
\hline MF GO term & $\%$ \\
\hline Catalytic activety & 44.1 \\
\hline Binding & 35.3 \\
\hline Transporter activety & 11.8 \\
\hline Electron carrier activety & 5.9 \\
\hline Structual molecule activety & 1.5 \\
\hline BP GO term & $\%$ \\
\hline Response to stress* & 12.0 \\
\hline Cellular metabolic process & 10.6 \\
\hline Response to chemical stimulus* & 9.9 \\
\hline Response to biotic stimulus* & 9.2 \\
\hline Response to other organism* & 9.1 \\
\hline Primary metabolic process & 6.3 \\
\hline Transport & 5.6 \\
\hline Response to endogeneous stimulus* & 4.2 \\
\hline Secondary metabolic process & 4.2 \\
\hline Biosynthetic process & 4.2 \\
\hline Macromolecule metabolic process & 3.5 \\
\hline Immune response ${ }^{*}$ & 2.8 \\
\hline Nitrogen compound metabolic process & 2.8 \\
\hline Response to abiotic stimulus* & 2.1 \\
\hline Regulation of biological process & 2.1 \\
\hline Transmembrane transport & 2.1 \\
\hline Catabolic process & 2.1 \\
\hline Small molecule metabolic process & 1.4 \\
\hline Oxidation-reduction process & 0.7 \\
\hline Aging & 0.7 \\
\hline Establishment of localization in cell & 0.7 \\
\hline Multicallular organism reproduction process & 0.7 \\
\hline Cell wall organization or biogengesis & 0.7 \\
\hline Cellular response to stimulus* & 0.7 \\
\hline Cell death & 0.7 \\
\hline
\end{tabular}

The 65 AtLBR-2-dependent up-regulated genes were classified by functional categories under the following GO terms: CC (level 2), MF (level 1), and BP (level 2) using the VirtualPlant 1.3 web service. BP GO terms related to stress and stimulus are indicated by asterisks
avrRpt2-induced gene 1 (AIG1), glutathione Stransferase 7 (GSTF7), and pleiotropic drug resistance 12 (PDR12), we could detect the significant differences between WT and the atlbr-2-1 at $24 \mathrm{~h}$ of pLPS treatments, indicating that AtLBR-2-dependent up-regulated genes identified by RNA-Seq were also confirmed by qRT-PCR. However, the expression levels of these 6 genes were not completely abolished in pLPS-treated atlbr-2-1 mutants. These results suggested the possibility that $A t L B R-1$, the paralog of AtLBR-2, may compensate for the absence of the AtLBR-2 gene. Therefore, we conducted qRT-PCR analysis for these 6 genes with the atlbr-1 mutant seedlings by the same method that was used on the atlbr2-1 mutant (Additional file 1: Figure S1) [8]. Similar to the results shown in Fig. 3, we detected significant differences in all tested genes in pLPS-treated WT and atlbr-1 mutants, suggesting that AtLBR-1 might also play an important role in some AtLBR-2-dependent upregulated genes. Furthermore, to exclude the possibility of contamination by other bacterial components, we purified the commercial pLPS. Seedlings were treated with purified pLPS and were analyzed by qRT-PCR (Additional file 1: Figure S2). Similar to the results shown in Fig. 3, we could detect the significant differences between WT and atlbr-21 in all of the genes tested at $24 \mathrm{~h}$ of purified pLPS treatments, confirming that this phenomenon was not caused by contamination.

Although we did not observe read counts from the region downstream of the T-DNA insertion site of AtLBR2 (Additional file 1: Figure S3), the possibility of slight expression of AtLBR-2 is not excluded because the TDNA insertion site of the atlbr-2-1 is located just next to the stop codon of the gene. Thereafter, we conducted qRT-PCR using the cDNA obtained from another pLPStreated T-DNA insertion line, atlbr-2-2 [8]. Similar to that in the atlbr-2-1, we could detect the significant differences between pLPS-treated WT and the atlbr-2-2 (Additional file 1: Figure S4).

\section{Validation of RNA-Seq data by qRT -PCR}

To validate RNA-Seq results, we conducted the expression analysis by qRT-PCR for randomly selected pLPSresponsive genes, including AtLBR-2-dependent or -independent up- or down-regulated genes. Figure 4 shows a comparison between the results from qRT-PCR and RNA-Seq analysis. For all 20 tested genes, transcript levels determined by qRT-PCR analysis were similar to those detected using RNA-Seq, indicating the reliability of the RNA-Seq data.

\section{A proposed pathway: AtLBR-2-mediated SAG accumulation} and following SA-related gene expression

In the WT, pLPS treatment induced differential expression of many genes related to SA, a potent inducer of 
Table 3 Pathway enrichment analysis of 65 AtLBR-2-dependent up-regulated genes

\begin{tabular}{|c|c|c|c|c|c|}
\hline Term & Pathway Database & Database ID & IN & $\mathrm{BN}$ & $P$-Value \\
\hline Camalexin biosynthesis & BioCyc & CAMALEXIN-SYN & 3 & 32 & 7.44E-05 \\
\hline Glutathione-mediated detoxification ॥ & BioCyc & PWY-6842 & 3 & 50 & 0.000258 \\
\hline Glutathione metabolism & KEGG & ath00480 & 3 & 93 & 0.001468 \\
\hline Cysteine and methionine metabolism & KEGG & ath00270 & 3 & 112 & 0.002458 \\
\hline Plant-pathogen interaction & KEGG & ath04626 & 3 & 167 & 0.007317 \\
\hline
\end{tabular}

A $P$-Value $<0.01$ was used as a threshold to select significant pathways. IN Input number, $B N$ Background number

pathogen-induced defense responses (Additional file 1: Table S5). Among these, 14 genes were identified as AtLBR-2-dependent up-regulated genes. In addition, 65 AtLBR-2-dependent up-regulated genes were responsible for the enrichment of GO term "response to SA stimulus" (Fig. 2). These RNA-Seq data analyses suggested the association of AtLBR-2 with pLPS-induced SA signaling. Therefore, first, we investigated whether pLPS-induced SA accumulation levels were altered in atlbr-2-1 plants. Treatment of both WT and the atlbr-2-1 with pLPS did not result in significant changes in the content of free SA (Fig. 5a, left panel). In contrast, the accumulation levels of conjugated SA glucoside (SAG) between WT and the atlbr-2-1 showed significant differences at $8 \mathrm{~h}$ after pLPS treatment (Fig. 5a, right panel). These results indicated that AtLBR-2 has an important role in pLPSinduced SAG accumulation. Furthermore, to confirm the relationship between AtLBR-2-mediated SAG accumulation and SA-related gene expression, we investigated the expression levels of 3 AtLBR-2-dependent upregulated genes, PR1, LURP1, and PDR12, in SA-treated WT plants and atlbr-2-1 mutants by qRT-PCR. These 3 genes are known as SA-related genes, and atlbr-2-1 mutants showed significant differences in the expression of these genes after pLPS treatment ([8] and Fig. 3). As shown in Fig. 5b, we observed the up-regulation of all tested genes in the SA-treated atlbr-2-1 to be at the same level, as or more, than that of WT plants. These results suggested that AtLBR-2 may act upstream of the SA signaling (SAG accumulation) pathway induced by pLPS treatment.

\section{Discussion}

Our primary interest in this study was in understanding the role of AtLBR-2 in LPS-induced plant defense responses. In a previous study, we concluded that apoplast-localized AtLBR-2 might play an important role in binding and transferring LPS to the LPS receptor. However, the functional properties of AtLBR-2 have not been characterized in detail. Therefore, in this study, we analyzed, for the first time, the effect of AtLBR-2 on transcriptional changes involved in pLPS treatment using RNA-Seq technology. By our RNA-Seq analysis, we identified that pLPS-induced up-regulated genes
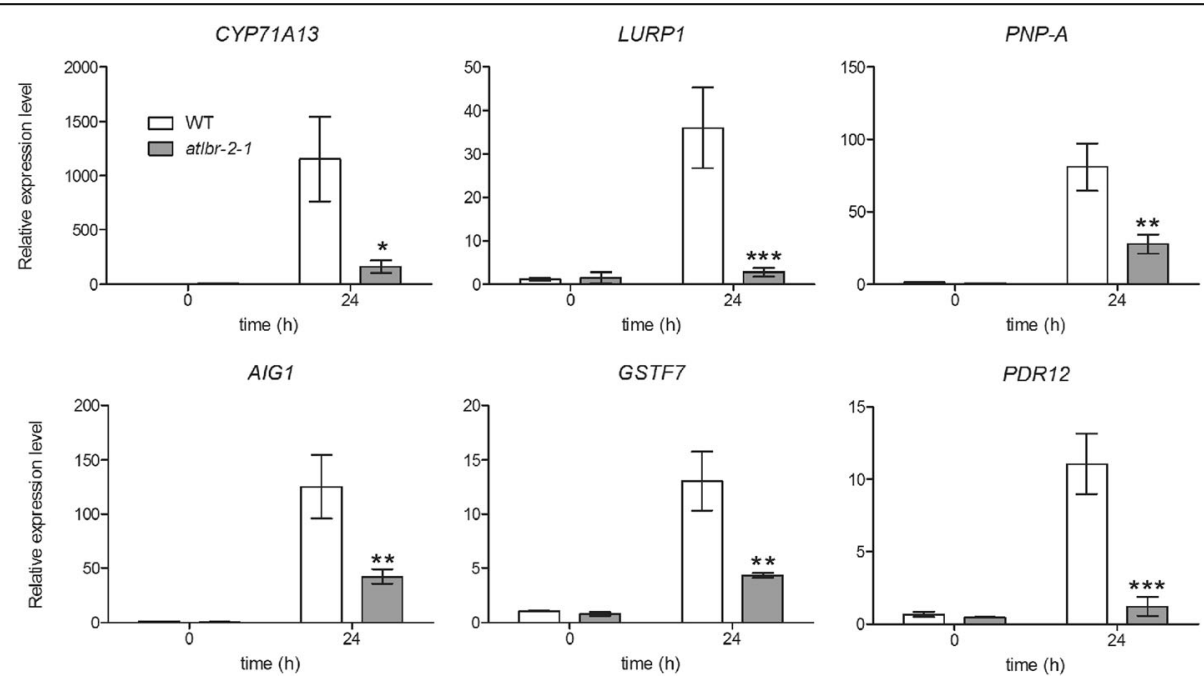

Fig. 3 qRT-PCR analysis of six AtLBR-2-dependent up-regulated genes. Among the 65 pLPS-induced AtLBR-2-dependent up-regulated genes, 6 defense-related genes (CYP71A13, LURP1, PNP-A, AIG1, GSTF7, and PDR12) were randomly selected and analyzed by qRT-PCR in WT and atlbr-2-1 plants treated with pLPS. The mean expression values were calculated from the results of three independent experiments. Means \pm standard errors are presented. Significant differences among the means were determined by two-way ANOVA followed by post hoc Bonferroni test compared to WT plants; ${ }^{*} P<0.05,{ }^{* *} P<0.01,{ }^{* * *} P<0.001$ 


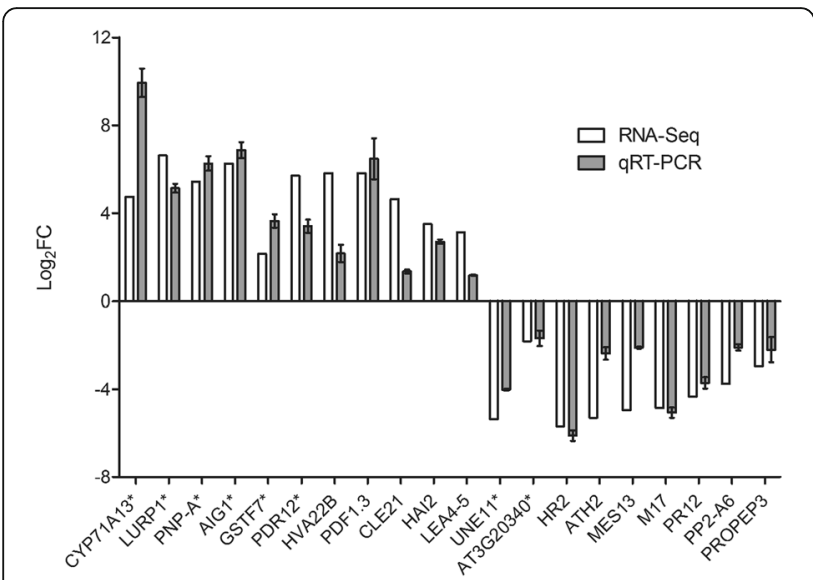

Fig. 4 Comparison of RNA-Seq results with those of qRT-PCR. The $\log _{2}$ FC values for transcript levels observed in RNA-Seq data (white bar) of randomly selected 20 genes, including AtLBR-2-dependent -independent up- or down-regulated genes, were compared to the results obtained from qRT-PCR (gray bar). AtLBR-2-dependent up- or down-regulated genes are indicated with asterisk: CYP71A13, LURP1, PNP-A, AIG1, GSTF7, PDR12, UNE11, and AT3G20340. AtLBR-2-independent up- or down-regulated genes are indicated without asterisk: HVA22B (AT5G62490), HVA22 homologue B; PDF1.3 (AT2G26010), plant defensin 1.3; CLE21 (AT5G64800), clavata3/ESR-related 21; HAl2 (AT1G07430), highly ABAinduced 2; LEA4-5 (AT5G06760), late embryogenesis abundant 4-5; HR2 (AT3G50460), homolog of RPW8 2; ATH2 (AT3G47740), A. thaliana ABC2 homolog 2; MES13 (AT1G26360), methyl esterase 13; M17 (AT2G41260), late embryogenesis abundant gene; PR12 (AT1G75830); PP2-A6 (AT5G45080), phloem protein 2-A6; PROPEP3 (AT5G64905), elicitor peptide 3 precursor were associated with defense-related, as well as metabolism-related processes, which is consistent with a previous study that used LPS from B. cepacia [9]. Furthermore, we found a strong association between AtLBR-2 and SA by our RNA-Seq analysis and, in fact, we demonstrated the reduced level of pLPS-induced SAG accumulation in the atlbr-2-1, and the SAinduced normal gene expression in atlbr-2-1 mutants. Our data revealed the importance of AtLBR-2 in SAmediating signaling pathway in response to LPS or when triggered by LPS.

\section{AtLBR-2 and SA signaling}

In this study, we identified 65 AtLBR-2-dependent genes that were up-regulated after pLPS treatment. The pathway analysis of these 65 genes revealed a significant enrichment of defense-related pathways. In fact, 44 of these genes encode proteins related to defense responses, and 14 genes, including PR1, LURP1, tyrosine aminotransferase 3 (TAT3), azelaic acid induced 1 (AZI1), peptide transporter 3 (PTR3), homolog of RPW8 4 (HR4), cysteine-rich receptor-like kinase (RLK) 5 (CRK5), elicitor-activated gene 3-2 (ELI3-2), flg22induced RLK 1 (FRK1), glutathione S-transferase 6 (GSTF6), cell wall-associated kinase 1 (WAK1), PDR12, AT2G25510, and AT5G03350, are known to be induced by SA (Additional file 1: Table S5). The SA signaling is mediated by at least two mechanisms, one requiring the NPR1 (NON-EXPRESSOR OF PR1) and the second,
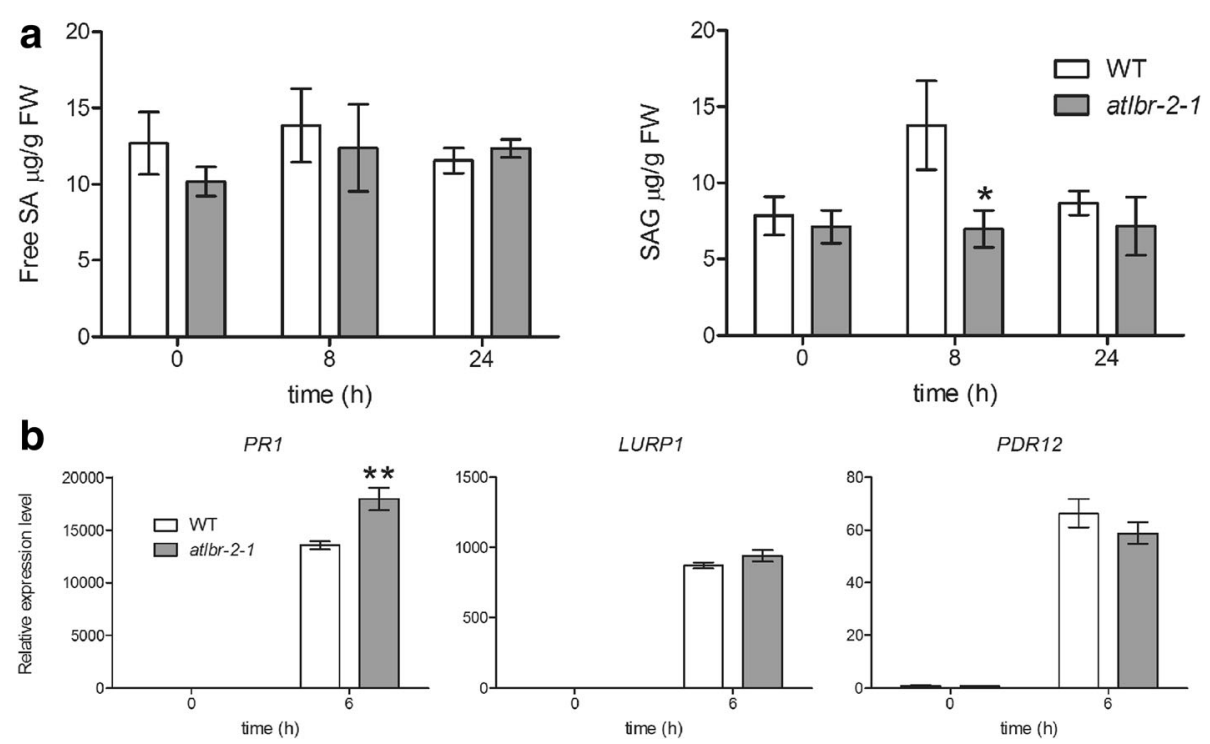

Fig. 5 pLPS-induced free SA and SAG accumulation and SA-induced gene expression. (a) Quantification of the total levels of free SA and SAG were measured by HPLC using samples extracted from Arabidopsis treated with pLPS for the indicated time. (b) Among the 65 pLPS-induced AtLBR-2-dependent up-regulated genes, the expression of the 3 SA-related genes (PR1, LURP1, and PDR12) were analyzed by qRT-PCR in WT and the atlbr-2-1 mutants plants treated with SA. The mean values were calculated from the results of three independent experiments. Means \pm standard errors are presented. Significant differences among the means were determined by two-way ANOVA followed by post hoc Bonferroni test compared to WT plants; ${ }^{*} P<0.05,{ }^{* *} P<0.01$. FW, fresh weight 
which is independent of NPR1 [6]. PR1 is well known as a marker for NPR1-dependent SA-induced pathway. In addition, Blanco et al. identified some NPR1-dependent SA-induced genes, including HR4, WAK1, and AT5G03350 by microarray analysis in SA-treated WT and npr 1-1 plants [10]. Furthermore, they also identified NPR1-independent SA-induced genes, including TAT3 and AT2G25510. These facts, along with our findings in this study, suggested the possibility that AtLBR-2 plays an important role in both NPR1-dependent and -independent signaling pathways triggered by LPS. Furthermore, we demonstrated that LPS-induced SAG accumulation was dependent on AtLBR-2. The LPSinduced accumulation of SAG, but not of SA, has been observed in previous studies, and might cause the transient production of $\mathrm{SA}$ and the stable accumulation of SAG [11]. In addition, the SA-treated atlbr-2-1 showed up-regulation of SA-related genes at levels similar to or more than those exhibited by WT plants. These results as well as our previous findings support the hypothesis that AtLBR-2 binds to LPS directly in the apoplastic region of Arabidopsis and, subsequently, induces the accumulation of SA (or SAG), leading to the activation of both NPR1-dependent and -independent signaling pathways and the gene expression that follows them [8].

Interestingly, NPR1 expression appeared to be upregulated after inoculation with $P$. syringae pv. tomato (Pst) DC3000 or upon SA treatment $[12,13]$; however, no difference was observed between the untreated and pLPStreated WT plants in the present study $(F D R<0.01)$. The WRKY transcription factors, including WRKY18, WRKY38, and WRKY53, reported to be the targets of NPR1 during SAR [14], appear to be down-regulated in the pLPS-treated WT plants (Additional file 1: Table S5). Shah suggested the existence of a negative feedback loop involving NPR1, which regulates the accumulation of SA [6]. Moreover, in the present study, we showed that SAG concentration returned to the basal levels after $24 \mathrm{~h}$ of pLPS treatment. Therefore, based on these observations, we speculated that long-term treatment of pLPS (24 h) might induce SA negative feedback loop involving NPR1 suppression and result in a decline in SA (SAG) to basal levels.

\section{AtLBR-2 and camalexin}

The 65 AtLBR-2-dependent up-regulated genes included CYP71A13 and phytoalexin deficient 3 (PAD3). These genes encode cytochrome $\mathrm{P} 450$ enzymes, which contribute to the enrichment of the "camalexin biosynthesis" pathway. Camalexin is an indole alkaloid phytoalexin produced by Arabidopsis that is thought to be important for resistance to necrotrophic fungal pathogens. A previous study revealed the LPS-induced camalexin production in plants [15]. CYP71A13 catalyzes the conversion of indole acetaldoxime to indole-3-acetonitrile, an intermediate in the camalexin biosynthesis [16]. PAD3 catalyzes the conversion of dihydrocamalexic acid to camalexin, which is the last step of camalexin biosynthesis [17]. Interestingly, Nafisi et al. demonstrated that the expression levels of $C Y P 71 A 13$ and PAD3 were coregulated in response to infection by $P$. syringae [16]. Furthermore, SA is required for camalexin synthesis, which is mediated by an NPR1-independent pathway $[18,19]$. These findings from previous research and the RNA-Seq analysis performed in this study led to the hypothesis that the binding and transfer of LPS to LPS receptor by AtLBR-2 and further SA (SAG) induction might be necessary to activate efficient LPS-induced camalexin biosynthesis. More research is needed to better understand the relationship between AtLBR-2 and camalexin biosynthesis in Arabidopsis.

\section{AtLBR-2 and ATPase}

Four genes (AT1G43910, AT3G28540, AT3G28580, and AT3G63380) encoding proteins that function as an ATPase were also among the 65 AtLBR-2-dependent upregulated genes. Relationship between the four genes and their defense responses have been reported previously. AT1G43910 and AT3G28540 were consistently higher in sni1, a transcription repressor of NPR1, when compared with the WT plants [20]. AT3G28580 has been used as singlet oxygen $\left({ }^{1} \mathrm{O}_{2}\right)$-responsive gene [21, 22]. ${ }^{1} \mathrm{O}_{2}$ is a singular ROS that can be produced by phytotoxins during plant-pathogen interactions [23]. In addition, Frei dit Frey showed that AT3G63380 (autoinhibited $\mathrm{Ca}^{2+}$-ATPase 12) cannot interact with FLS2, the bacterial flagellin peptide flg22 receptor, but might contribute to the control of cytosolic $\mathrm{Ca}^{2+}$ levels during flg22 responses [24]. Furthermore, a previous report described the relationship between the plasma membrane ATPase of plants and PAMPs-induced rapid extracellular alkalinization [25]. These reports lead us to speculate that AtLBR-2 might be related to LPS-induced ATPaserelated responses, e.g. extracellular alkalinization and $\mathrm{Ca}^{2+}$ influx/efflux.

\section{AtLBR-2 and protein kinases}

For understanding the LPS recognition mechanism(s), it is essential to investigate the LPS receptor that binds to LPS and initiates a signaling cascade inside the cell via its kinase activity. The well known PAMPs, including flg22, bacterial elongation factor $\mathrm{Tu}$ (EF-Tu) peptide elf18, and fungal cell wall component chitin, are recognized by pattern recognition receptors, flagellin-sensitive 2 (FLS2), EF-Tu receptor (EFR), and chitin elicitor receptor kinase 1 (CERK1), respectively [26]. Interestingly, the genes induced or repressed by PAMPs are clearly correlated. The flg22 treatment induced the expression not only of EFR and CERK1, in addition to that of FLS2 
[27]. In this study, we identified seven AtLBR-2dependent up-regulated genes, which encode protein kinases (CRK5, CRK38, FRK1, WAK1, AT1G51820, AT1G67520, and AT4G17660). The bulb-type lectin Sdomain-1 RLK LORE (AT1G61380), which is required for sensing of LPS from Pseudomonas and Xanthomonas species [28], was not, but lectin protein kinase family protein (AT1G67520) was included in the list. AT1G67520 is known as G-type lectin RLK and is similar to LORE; however, it lacks the transmembrane region [29]. Interestingly, both flg22 and elf26 treatments induced LORE and AT1G67520 [27]. These results suggest that AT1G67520 might be involved in recognition of LPS or other related PAMPs. The LPS-responsive Sdomain RLK (Nt-Sd-RLK) was also identified in Nicotiana tabacum [30]. Signal transduction via RLKs seems to be required for the activation of LPS-induced plant defense responses. We also focused on CRK5, which is potential target gene of WRKY transcription factors. Chen et al. reported that CRK5 expression was upregulated by SA treatment and constitutive overexpression of CRK5 led to increased resistance to Pst DC3000, which was associated with rapidly induced expression of PR1 after pathogen infection [31]. Moreover, we also focused on leucine-rich repeat (LRR) protein kinase family protein encoded by AT1G51820, because FLS2, EFR, and their co-receptor brassinosteroid insensitive 1 (BRI1)-associated receptor kinase 1 (BAK1) belong to the LRR-RLK family. Interestingly, AT1G51820 expression was up-regulated after infection with oomycete downy mildew pathogen [32]. These studies suggest that AtLBR-2-related protein kinases might be involved in the perception of PAMP. We speculate on possible LPS perception systems via unknown protein kinases other than LORE or those, which cooperate with LORE.

\section{Conclusion}

In summary, we have reported here the first analysis of the genome-wide effect of AtLBR-2 on pLPS-induced gene expression. The transcriptome analyses performed in this study identify the 65 AtLBR-2-dependent up-regulated genes, and reveal the indispensable role of AtLBR-2 in the up-regulation of pLPS-induced genes associated with defense responses. Further experiments also suggested the existence of an SA-mediated LPS signaling system via AtLBR-2. Thus, we suggest that 65 AtLBR-2-related proteins might be the key candidate molecules in LPS-induced defense mechanisms in plants.

\section{Methods}

Arabidopsis growth conditions and pLPS or SA treatment Arabidopsis ecotype Col-0 was used as the wild-type (WT) plants in this study. All mutants were in the Col background. After $5 \mathrm{~d}$ of growth on MS agar plates at
22-24 ${ }^{\circ} \mathrm{C}$ under a $16 \mathrm{~h}$ light/ $8 \mathrm{~h}$ dark cycle, the seedlings were transferred to two separate liquid MS medium supplemented with $100 \mu \mathrm{g} / \mathrm{ml}$ LPS from $P$. aeruginosa serotype 10 (pLPS; Sigma-Aldrich Japan, Tokyo, Japan) and $200 \mu \mathrm{M}$ SA (Wako, Osaka, Japan) that were then kept under continuous light conditions for $24 \mathrm{~h}$ and $6 \mathrm{~h}$, respectively. Untreated seedlings were used as controls $(0 \mathrm{~h})$. The experiments were performed in three biological replicates.

\section{RNA sample preparation and high-throughput sequencing}

After the treatment, the seedlings were powdered in liquid nitrogen and RNA was extracted using the plant total RNA extraction Miniprep system (Viogene, Taipei, Taiwan) according to the manufacturer's instructions. The quality of total RNA obtained from pLPS-treated or untreated seedlings was evaluated using the value of RNA Integrity Number (RIN) in the Agilent Bioanalyzer 2100 (Agilent, Santa Clara, CA, USA). The total RNA concentration was measured using a Qubit RNA assay kit (Thermo Fisher Scientific, Waltham, MA, USA). The mRNAs were purified from 100 ng total RNAs by NEBNext Poly(A) mRNA Magnetic Isolation Module (New England Biolabs, Ipswich, MA, USA), according to the manufacturer's instructions. The sequencing libraries were prepared by NEBNext Ultra Directional RNA Library Prep Kit for Illumina (New England Biolabs, Ipswich, MA, USA), according to the manufacturer's instructions. The quality of the libraries was assessed by a microchip electrophoresis system (MCE-202 MultiNA; Shimadzu, Kyoto, Japan) and their quantities were measured by Qubit dsDNA BR assay kit (Thermo Fisher Scientific, Waltham, MA, USA). After equimolar amounts of the libraries were pooled, they were used for pairedend read sequencing $(2 \times 101 \mathrm{bp})$ on Illumina Hiseq 4000 (Illumina, San Diego, CA, USA).

\section{Read mapping and transcript assembly}

After the quality evaluation and removal of adaptercontaining reads, more than $88 \%$ left and right reads could be mapped to the Arabidopsis TAIR 10 genomes using TopHat software (http://www.ccb.jhu.edu/software/tophat/) (Additional file 1: Table S6) [33]. The concordant pair alignment rate was more than $86 \%$. The transcripts were assembled and fragments per kilobase of transcript per million fragments mapped (FPKM) were estimated using Cufflinks software (http://cole-trapnell-lab.github.io/cufflinks/) (Additional file 2: Table S7) [33].

\section{Identification of AtLBR-2-dependent up- or down- regulated genes}

The differential expression between pLPS-treated WT and the three other data sets (untreated WT, pLPS- 
treated atlbr-2-1, and untreated atlbr-2-1) were calculated in $\mathrm{R}$ packages, edgeR (https://bioconductor.org/ packages/release/bioc/html/edgeR.html) [34] and TCC (http://bioconductor.org/packages/release/bioc/html/TC C.html) [35] using the read counts of each data set, which were calculated by HTSeq-count (https://htseq.readthedocs.io/en/release_0.9.1/index.html) [36]. When compared to RNA-Seq data obtained from pLPS-treated WT, genes with negative Log fold change $\left(\log _{2} \mathrm{FC}\right)$ value changes (FDR; false discovery rate $<0.01, \log _{2} \mathrm{FC}<-1.35$ ) were identified as up-regulated genes in pLPS-treated WT. In contrast, genes with positive $\log _{2} \mathrm{FC}$ value changes $\left(\mathrm{FDR}<0.01, \log _{2} \mathrm{FC}>1.35\right.$ ) were identified as down-regulated genes in pLPS-treated WT. Commonly up-regulated or down-regulated genes were investigated and 65 and 2 genes were identified as AtLBR-2-dependent up- and down-regulated genes, respectively.

\section{Gene ontology (GO) enrichment analysis}

The GO enrichment analysis for pLPS-induced up- or down-regulated genes in the WT plants was performed using functional annotation charts of DAVID Bioinformatics Resources 6.7 (https://david-d.ncifcrf.gov/) [37]. The distributions of GO terms at levels 1 or 2 for $\mathrm{CC}, \mathrm{MF}$, and $\mathrm{BP}$ for the 65 AtLBR-2-dependent up-regulated genes were analyzed using the VirtualPlant 1.3 online tool (http://virtualplant.bio.nyu.edu/cgi-bin/vpweb/) [38].

\section{Pathway analysis}

The pathway analysis of the 65 AtLBR-2-dependent upregulated genes was performed via KOBAS 3.0 (http:// kobas.cbi.pku.edu.cn/), which uses the BioCyc (https:// biocyc.org/), KEGG (http://www.genome.jp/kegg/), and PANTHER (http://pantherdb.org/) databases [39, 40]. Only pathways with $P$-value $<0.01$ were listed.

\section{Real-time PCR (qRT-PCR) analysis}

After the pLPS or SA treatment and total RNA isolation, as above, reverse transcription was performed using $1 \mu \mathrm{g}$ of total RNA [8]. qRT-PCR was run on a PikoReal realtime PCR system (Thermo Fisher Scientific, Waltham, MA, USA), according to the manufacturer's recommendations using the following conditions: $1 \mathrm{~min}$ at $95{ }^{\circ} \mathrm{C}$, and 40 cycles of $5 \mathrm{~s}$ at $95{ }^{\circ} \mathrm{C}$ and $30 \mathrm{~s}$ at $60{ }^{\circ} \mathrm{C}$. Because the FPKM values of $\beta$-tubulin4 (AT5G44340) were not affected by pLPS treatment, it was used as a nonresponsive reference gene (Additional file 1: Fig. S5). The sequences of gene-specific primers are mentioned in Table S4 (Additional file 1). Each experiment was repeated at least three times.

\section{Free SA and SAG measurement}

Two-week-old Arabidopsis seedlings grown on MS agar plates were transferred to liquid MS medium and treated with $100 \mu \mathrm{g} / \mathrm{ml}$ pLPS for the indicated time points. After the treatment, $80 \mathrm{mg}$ of whole plants were harvested. Both free SA and SAG extraction was performed, based on a previously-reported method [41, 42]. Free SA and SAG were quantified by reverse-phase HPLC on a C18 column (YMC, Kyoto, Japan) and monitored by UVdetection at $240 \mathrm{~nm}$. The column was eluted with 50 to $90 \%$ acetonitrile gradient in water containing $0.1 \%$ trifluoroacetic acid.

\section{Additional files}

Additional file 1:Table S1-S6. and Figure S1-S5. (PDF 579 kb)

Additional file 2: Table S7. The FPKM of all transcripts in each data sets. (XLSX $4687 \mathrm{~kb})$

\section{Abbreviations}

ABA: abscisic acid; AtLBR-2: Arabidopsis LBP/BPI-related 2; BP: biological process; BPI: bactericidal/permeability-increasing protein; CC: cellular component; FDR: false discovery rate; GO: gene ontology; LBP: LPS-binding protein; $\log _{2}$ FC: log fold change; LPS: lipopolysaccharide; MF: molecular function; NPR1: non-expressor of PR1; PAMP: pathogen-associated molecular pattern; pLPS: commercial LPS from Pseudomonas aeruginosa;

PR1: pathogenesis-related 1; RNA-Seq: mRNA sequencing; SA: salicylic acid; SAG: conjugated SA glucoside

\section{Acknowledgements}

We are grateful to Dr. S. Mitsutake and Dr. T. Ueda of Saga University for their support and helpful suggestions. We also want to thank our research assistant, Ms. A. Sakai, for her tireless assistance.

\section{Funding}

This work was supported by Research grant for advanced research, United Graduate School of Agricultural Sciences, Kagoshima University.

\section{Availability of data and materials}

The RNA-Seq raw data (Additional file 1: Table S6) presented in this paper were downloaded from the DNA Data Bank of Japan (DDBJ) (ftp://ftp.ddbj. nig.ac.jp/ddbj_database/dra/fastq/DRA005/DRA005496).

\section{Authors' contributions \\ $\mathrm{SI}, \mathrm{El}$, and YN designed the study and wrote the manuscript; SI, El, KW, and YN performed the bioinformatic analysis and analyzed the data; $\mathrm{SI}$ and $\mathrm{El}$ performed the experiments. All authors read and approved the final manuscript.}

Ethics approval and consent to participate

Not applicable.

Consent for publication

Not applicable.

\section{Competing interests}

The authors declare that the research was conducted in the absence of any commercial or financial relationships that could be construed as a potential conflict of interest.

\section{Publisher's Note}

Springer Nature remains neutral with regard to jurisdictional claims in published maps and institutional affiliations.

\section{Author details}

${ }^{1}$ Analytical Research Center for Experimental Sciences, Saga University, Saga, Japan. ${ }^{2}$ Department of Biological Resource Sciences, Graduate School of Agriculture, Saga University, Saga, Japan. ${ }^{3}$ Department of Biological Science and Technology, The United Graduate School of Agricultural Sciences, 
Kagoshima University, Kagoshima, Japan. ${ }^{4}$ Department of Immunology, Graduate School of Medical and Dental Sciences, Kagoshima University, Kagoshima, Japan

Received: 14 March 2017 Accepted: 8 December 2017

Published online: 29 December 2017

\section{References}

1. Ranf S. Immune sensing of lipopolysaccharide in plants and animals: same but different. PLoS Pathog. 2016;12:e1005596.

2. Desaki Y, Miya A, Venkatesh B, Tsuyumu S, Yamane H, Kaku H, et al. Bacterial lipopolysaccharides induce defense responses associated with programmed cell death in rice cells. Plant Cell Physiol. 2006:47:1530-40.

3. Zeidler D, Zähringer U, Gerber I, Dubery I, Hartung T, Bors W, et al. Innate immunity in Arabidopsis Thaliana: lipopolysaccharides activate nitric oxide synthase (NOS) and induce defense genes. Proc Natl Acad Sci. 2004;101: 15811-6.

4. Mishina TE, Zeier J. Pathogen-associated molecular pattern recognition rather than development of tissue necrosis contributes to bacterial induction of systemic acquired resistance in Arabidopsis. Plant J. 2007;50: 500-13.

5. Melotto M, Underwood W, Koczan J, Nomura K, He SY. Plant stomata function in innate immunity against bacterial invasion. Cell. 2006;126:969-80.

6. Shah J. The salicylic acid loop in plant defense. Curr Opin Plant Biol. 2003;6: 365-71.

7. Weiss J. Bactericidal/permeability-increasing protein (BPI) and lipopolysaccharide-binding protein (LBP): structure, function and regulation in host defence against gram-negative bacteria. Biochem Soc Trans. 2003; 31:785-90.

8. lizasa S, lizasa E, Matsuzaki S, Tanaka H, Kodama Y, Watanabe K, et al. Arabidopsis LBP/BPI related-1 and -2 bind to LPS directly and regulate PR1 expression. Sci Rep. 2016;6:27527.

9. Madala NE, Molinaro A, Dubery IA. Distinct carbohydrate and lipid-based molecular patterns within lipopolysaccharides from Burkholderia cepacia contribute to defense-associated differential gene expression in Arabidopsis Thaliana. Innate Immun. 2012;18:140-54.

10. Blanco F, Salinas P, Cecchini NM, Jordana X, Hummelen PV, Alvarez ME, et al. Early genomic responses to salicylic acid in Arabidopsis. Plant Mol Biol. 2009;70:79-102

11. Zeidler D, Dubery IA, Schmitt-Kopplin P, Von Rad U, Durner J. Lipopolysaccharide mobility in leaf tissue of Arabidopsis Thaliana. Mol Plant Pathol. 2010;11:747-55.

12. Lim CW, Luan S, Lee SCA. Prominent role for RCAR3-mediated ABA signaling in response to pseudomonas syringae pv. Tomato DC3000 infection in Arabidopsis. Plant Cell Physiol. 2014;55:1691-703.

13. Datta $R$, Sinha $R$, Chattopadhyay $S$. Changes in leaf proteome profile of Arabidopsis Thaliana in response to salicylic acid. J Biosci. 2013;38:317-28.

14. Ishihama N, Yoshioka H. Post-translational regulation of WRKY transcription factors in plant immunity. Curr Opin Plant Biol. 2012;15:431-7.

15. Beets CA, Huang J-C, Madala NE, Dubery I. Activation of camalexin biosynthesis in Arabidopsis Thaliana in response to perception of bacterial lipopolysaccharides: a gene-to-metabolite study. Planta. 2012;236:261-72.

16. Nafisi M, Goregaoker S, Botanga CJ, Glawischnig E, Olsen CE, Halkier BA, et al. Arabidopsis cytochrome P450 monooxygenase 71A13 catalyzes the conversion of indole-3-acetaldoxime in camalexin synthesis. Plant Cell. 2007; 19:2039-52.

17. Schuhegger R, Nafisi M, Mansourova M, Petersen BL, Olsen CE, Svatoš A, et al. CYP71B15 (PAD3) catalyzes the final step in camalexin biosynthesis. Plant Physiol. 2006;141:1248-54.

18. Zhao J, Last RL. Coordinate regulation of the tryptophan biosynthetic pathway and indolic phytoalexin accumulation in Arabidopsis. Plant Cell. 1996:8:2235-44.

19. Glazebrook J, Rogers EE, Ausubel FM. Isolation of Arabidopsis mutants with enhanced disease susceptibility by direct screening. Genetics. 1996;143:973-82

20. Mosher RA, Durrant WE, Wang D, Song J, Dong X. A comprehensive structure-function analysis of Arabidopsis SNI1 defines essential regions and transcriptional repressor activity. Plant Cell. 2006;18:1750-65.

21. Kim C, Meskauskiene R, Zhang S, Lee KP, Ashok ML, Blajecka K, et al. Chloroplasts of Arabidopsis are the source and a primary target of a plantspecific programmed cell death signaling pathway. Plant Cell. 2012;24:3026-39.
22. Šimková K, Moreau F, Pawlak P, Vriet C, Baruah A, Alexandre C, et al. Integration of stress-related and reactive oxygen species-mediated signals by topoisomerase VI in Arabidopsis Thaliana. Proc Natl Acad Sci. 2012;109: 16360-5.

23. Triantaphylidès $C$, Havaux M. Singlet oxygen in plants: production, detoxification and signaling. Trends Plant Sci. 2009:14:219-28.

24. Dit FNF, Mbengue $M$, Kwaaitaal M, Nitsch L, Altenbach D, Häweker $H$, et al. Plasma membrane calcium ATPases are important components of receptormediated signaling in plant immune responses and development. Plant Physiol. 2012;159:798-809.

25. Elmore JM, Coaker $\mathrm{G}$. The role of the plasma membrane $\mathrm{H}^{+-}$ATPase in plant-microbe interactions. Mol Plant. 2011;4:416-27.

26. Segonzac C, Zipfel C. Activation of plant pattern-recognition receptors by bacteria. Curr Opin Microbiol. 2011;14:54-61.

27. Zipfel C, Kunze G, Chinchilla D, Caniard A, Jones JDG, Boller T, et al. Perception of the bacterial PAMP EF-Tu by the receptor EFR restricts agrobacterium-mediated transformation. Cell. 2006;125:749-60.

28. Ranf S, Gisch N, Schäffer M, Illig T, Westphal L, Knirel YA, et al. A lectin Sdomain receptor kinase mediates lipopolysaccharide sensing in Arabidopsis Thaliana. Nat Immunol. 2015;16:426-33.

29. Vaid N, Pandey PK, Tuteja N. Genome-wide analysis of lectin receptor-like kinase family from Arabidopsis and rice. Plant Mol Biol. 2012;80:365-88.

30. Sanabria NM, van Heerden $H$, Dubery IA. Molecular characterisation and regulation of a Nicotiana Tabacum S-domain receptor-like kinase gene induced during an early rapid response to lipopolysaccharides. Gene. 2012; 501:39-48.

31. Chen F, D'Auria JC, Tholl D, Ross JR, Gershenzon J, Noel JP, et al. An Arabidopsis Thaliana gene for methylsalicylate biosynthesis, identified by a biochemical genomics approach, has a role in defense. Plant J. 2003;36:577-88.

32. Hok S, Danchin EGJ, Allasia V, Panabières F, Attard A, Keller H. An Arabidopsis (malectin-like) leucine-rich repeat receptor-like kinase contributes to downy mildew disease. Plant Cell Environ. 2011:34:1944-57.

33. Trapnell C, Roberts A, Goff L, Pertea G, Kim D, Kelley DR, et al. Differential gene and transcript expression analysis of RNA-seg experiments with TopHat and cufflinks. Nat Protoc. 2012;7:562-78.

34. Robinson MD, McCarthy DJ, Smyth GK. edgeR: a bioconductor package for differential expression analysis of digital gene expression data. Bioinformatics. 2010:26:139-40.

35. Sun J, Nishiyama T, Shimizu K, Kadota KTCC. An R package for comparing tag count data with robust normalization strategies. BMC Bioinformatics. 2013;14:219.

36. Anders S, Pyl PT, Huber W. HTSeq-a python framework to work with highthroughput sequencing data. Bioinformatics. 2015;31:166-9.

37. Huang DW, Sherman BT, Lempicki RA. Systematic and integrative analysis of large gene lists using DAVID bioinformatics resources. Nat Protoc. 2008;4: 44-57.

38. Katari MS, Nowicki SD, Aceituno FF, Nero D, Kelfer J, Thompson LP, et al. VirtualPlant: a software platform to support systems biology research. Plant Physiol. 2010;152:500-15.

39. Xie C, Mao X, Huang J, Ding Y, Wu J, Dong S, et al. KOBAS 2.0: a web server for annotation and identification of enriched pathways and diseases. Nucleic Acids Res. 2011;39(suppl 2):W316-22.

40. Wu J, Mao X, Cai T, Luo J, Wei LKOBAS. Server: a web-based platform for automated annotation and pathway identification. Nucleic Acids Res. 2006; 34(suppl 2):W720-4

41. Li X, Zhang Y, Clarke JD, Li Y, Dong X. Identification and cloning of a negative regulator of systemic acquired resistance, SNI1, through a screen for suppressors of npr1-1. Cell. 1999;98:329-39.

42. Bowling SA, Guo A, Cao H, Gordon AS, Klessig DF, Dong X. A mutation in Arabidopsis that leads to constitutive expression of systemic acquired resistance. Plant Cell. 1994;6:1845-57.

43. Uknes S, Mauch-Mani B, Moyer M, Potter S, Williams S, Dincher S, et al. Acquired resistance in Arabidopsis. Plant Cell. 1992;4:645-56.

44. Bricchi I, Bertea CM, Occhipinti A, Paponov IA, Maffei ME. Dynamics of membrane potential variation and gene expression induced by Spodoptera Littoralis, Myzus Persicae, and pseudomonas syringae in Arabidopsis. PLoS One. 2012;7:e46673.

45. Morán-Diez E, Rubio B, Domínguez S, Hermosa R, Monte E, Nicolás C. Transcriptomic response of Arabidopsis Thaliana after $24 \mathrm{~h}$ incubation with the biocontrol fungus Trichoderma harzianum. J Plant Physiol. 2012;169:614-20. 
46. Borges AA, Dobon A, Expósito-Rodríguez M, Jiménez-Arias D, Borges-Pérez A Casañas-Sánchez $V$, et al. Molecular analysis of menadione-induced resistance against biotic stress in Arabidopsis. Plant Biotechnol J. 2009;7:744-62.

47. Van LLC, Rep M, CMJ P. Significance of inducible defense-related rroteins in infected plants. Annu Rev Phytopathol. 2006;44:135-62.

48. Kus JV, Zaton K, Sarkar R, Cameron RK. Age-related resistance in Arabidopsis is a developmentally regulated defense response to pseudomonas syringae. Plant Cell Online. 2002;14:479-90.

49. Bourdais G, Burdiak P, Gauthier A, Nitsch L, Salojärvi J, Rayapuram C, et al. Large-scale phenomics identifies primary and fine-tuning roles for CRKs in responses related to oxidative stress. PLoS Genet. 2015;11:e1005373.

50. Breitenbach $\mathrm{HH}$, Wenig M, Wittek F, Jordá L, Maldonado-Alconada AM, Sarioglu $\mathrm{H}$, et al. Contrasting roles of the APOPLASTIC aspartyl protease APOPLASTIC, ENHANCED DISEASE SUSCEPTIBILITY1-DEPENDENT1 and LEGUME LECTIN-LIKE PROTEIN1 in Arabidopsis systemic acquired resistance. Plant Physiol. 2014;165:791-809.

51. Jakab G, Manrique A, Zimmerli L, Métraux J-P, Mauch-Mani B. Molecular characterization of a novel lipase-like pathogen-inducible gene family of Arabidopsis. Plant Physiol. 2003;132:2230-9.

52. Jung HW, Tschaplinski TJ, Wang L, Glazebrook J, Greenberg JT. Priming in systemic plant immunity. Science. 2009;324:89-91.

53. Reuber TL, Ausubel FM. Isolation of Arabidopsis genes that differentiate between resistance responses mediated by the RPS2 and RPM1 disease resistance genes. Plant Cell Online. 1996;8:241-9.

54. Mészáros T, Helfer A, Hatzimasoura E, Magyar Z, Serazetdinova L, Rios G, et al. The Arabidopsis MAP kinase kinase MKK1 participates in defence responses to the bacterial elicitor flagellin. Plant J. 2006;48:485-98.

55. Denoux C, Galletti R, Mammarella N, Gopalan S, Werck D, De Lorenzo G, et al. Activation of defense response pathways by OGs and Flg22 elicitors in Arabidopsis seedlings. Mol Plant. 2008;1:423-45.

56. Du Z, Xu D, Li L, Shi Y, Schläppi M, Xu Z-Q. Inhibitory effects of Arabidopsis EARLI1 against Botrytis Cinerea and Bradysia Difformis. Plant Cell Tissue Organ Cult PCTOC. 2012;110:435-43.

57. Karim S, Holmström K-O, Mandal A, Dahl P, Hohmann S, Brader G, et al. AtPTR3, a wound-induced peptide transporter needed for defence against virulent bacterial pathogens in Arabidopsis. Planta. 2006;225:1431-45.

58. Asano T, Kimura M, Nishiuchi T. The defense response in Arabidopsis Thaliana against fusarium sporotrichioides. Proteome Sci. 2012;10:61.

59. Chen K, Fan B, Du L, Chen Z. Activation of hypersensitive cell death by pathogen-induced receptor-like protein kinases from Arabidopsis. Plant Mol Biol. 2004;56:271-83.

60. Quirino BF, Normanly J, Amasino RM. Diverse range of gene activity during Arabidopsis Thaliana leaf senescence includes pathogen-independent induction of defense-related genes. Plant Mol Biol. 1999;40:267-78.

61. Yi SY, Shirasu K, Moon JS, Lee S-G, Kwon S-Y. The activated SA and JA signaling pathways have an influence on flg22-triggered oxidative burst and callose deposition. PLoS One. 2014;9:e88951.

62. Gruner K, Griebel T, Návarová H, Attaran E, Zeier J. Reprogramming of plants during systemic acquired resistance. Front Plant Sci. 2013;4:252.

63. Lieberherr D, Wagner U, Dubuis P-H, Métraux J-P, Mauch F. The rapid induction of glutathione S-transferases AtGSTF2 and AtGSTF6 by avirulent pseudomonas syringae is the result of combined salicylic acid and ethylene signaling. Plant Cell Physiol. 2003;44:750-7.

64. Tsuda K, Sato M, Glazebrook J, Cohen JD, Katagiri F. Interplay between MAMPtriggered and SA-mediated defense responses. Plant J. 2008:53:763-75.

65. Blanco F, Garretón V, Frey N, Dominguez C, Pérez-Acle T, der Straeten DV, et al. Identification of NPR1-dependent and independent genes early induced by salicylic acid treatment in Arabidopsis. Plant Mol Biol. 2005;59:927-44.

66. Siemens J, Keller I, Sarx J, Kunz S, Schuller A, Nagel W, et al. Transcriptome analysis of Arabidopsis clubroots indicate a key role for cytokinins in disease development. Mol Plant-Microbe Interact. 2006;19:480-94.

67. Gechev TS, Gadjev IZ, Hille J. An extensive microarray analysis of AAL-toxininduced cell death in Arabidopsis Thaliana brings new insights into the complexity of programmed cell death in plants. Cell Mol Life Sci CMLS. 2004;61:1185-97.

68. Bethke G, Grundman RE, Sreekanta S, Truman W, Katagiri F, Glazebrook J, Arabidopsis PECTINMETHYLESTERASE. Contribute to immunity against pseudomonas syringae. Plant Physiol. 2014;164:1093-107.

69. Ferrari S, Galletti R, Denoux C, Lorenzo GD, Ausubel FM, Dewdney J. Resistance to Botrytis Cinerea induced in Arabidopsis by elicitors is independent of salicylic acid, ethylene, or jasmonate signaling but requires PHYTOALEXIN DEFICIENT3. Plant Physiol. 2007;144:367-79.

70. Campbell EJ, Schenk PM, Kazan K, Penninckx IAMA, Anderson JP, Maclean DJ, et al. Pathogen-responsive expression of a putative ATP-binding cassette transporter gene conferring resistance to the diterpenoid sclareol is regulated by multiple defense signaling pathways in Arabidopsis. Plant Physiol. 2003;133:1272-84

\section{Submit your next manuscript to BioMed Central and we will help you at every step:}

- We accept pre-submission inquiries

- Our selector tool helps you to find the most relevant journal

- We provide round the clock customer support

- Convenient online submission

- Thorough peer review

- Inclusion in PubMed and all major indexing services

- Maximum visibility for your research

Submit your manuscript at www.biomedcentral.com/submit
) Biomed Central 